\title{
APROVECHAMIENTO DE AGUAS SUBTERRÁNEAS EN EL INTERIOR VALENCIANO
}

Gabino Ponce Herrero

\begin{abstract}
RESUMEN
El espacio interior de la Comunidad Valenciana presenta en la actualidad destacados índices de desarrollo agrícola merced, entre otros factores, a la expansión del regadío. Comarca pionera fue la del Vinalopó (Alicante), seguida por otras que deben su bonificación a la expansión interior de los fértiles regadíos litorales. Hoy, los diferentes tipos de tenencia del agua y las formas de uso desplegadas para su aprovechamiento se concretan en Comunidades de Regantes, Sociedades Agrarias de Transformación, sociedades mercantiles y pequeños propietarios de pozos, rectores del mercado del agua, que constituye en ese ámbito un decisivo factor de progreso económico.
\end{abstract}

\section{SUMMARY}

The inland areas of the Valencian Community are currently enjoying a high level of agricultural development due to, among other things, the spread of irrigation. The Vinalopó area in Alicante was the first to experience this growth, and improvement in other regions was due to the inward expansion of fertile coastal irrigation lands. Today, the different types of water ownership or tenancy include Associations of Irrigators, Agrarian Transformation Societies, mercantile societies and individual well owners. These organizations and individuals devise and administer plans for water usage and distribution, and are an important factor in the economic progress of the region.

\section{Introducción}

De acuerdo con unas características climáticas y edáficas poco favorables al desarrollo de cultivos exigentes, las comarcas del interior valenciano han basado su economía agraria en las explotaciones de secano, extendidas por los glacis y piedemontes de los valles corredores y por los altiplanos, de condiciones análogas a las imperantes en los confines de la submeseta meridional.

En ese ámbito, multitud de pequeñas huertas encuentran cabida en el lecho de los grandes ríos alóctonos valencianos $\mathrm{y}$ en algunos cursos menores, con una producción que 


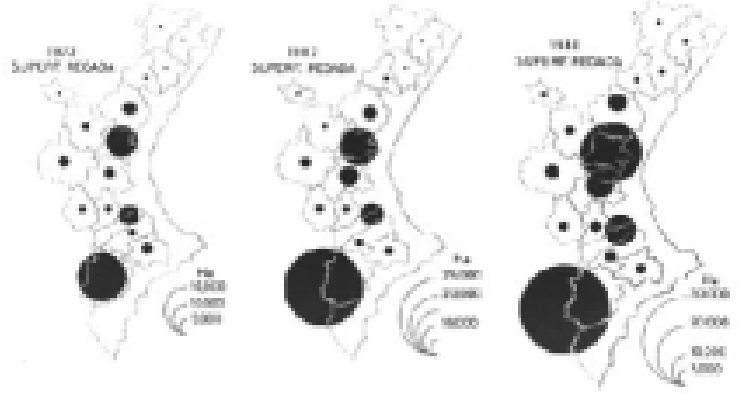

FIGURA 1. Evolución de la superficie regada en las comarcas del interior valenciano. El Vinalopó, en Alicante, y el Campo de Liria y la Hoya de Buñol, en Valencia, presentan las mayores magnitudes. Fuente: Censos agrarios, 1972, 1982 y Conselleria Agricultura, 1988 (hojas 1-T). Elaboración propia. 
apenas excede la demanda generada en los mismos municipios, con una clara vocación autárquica.

Sin embargo, en el último cuarto de siglo (y en fechas más tempranas en el Vinalopó) se han ido desarrollando grandes transformaciones en el campo del interior valenciano gracias al aprovechamiento intensificado de las aguas subterráneas, elevadas y distribuidas para bonificar nuevos cultivos, o mejorar la producción de algunos tradicionales. El impresionante esfuerzo se plasma en el incremento incesante de la superficie regada (en cifras absolutas) y en la conversión de lánguidos cultivos extensivos y eriales en fértiles plantaciones arbóreas, arbustivas y herbáceas, que han supuesto una importante movilización de recursos técnicos, económicos y humanos, en una mutación del paisaje que ha devuelto la rentabilidad a un espacio agrario antes poco atractivo.

En cifras absolutas, la superficie de regadío de las comarcas no litorales de la Comunidad Valenciana ha pasado de las 55.032 Ha de 1972 a las 69.011 Ha de 1982 y a las 95.513 Ha de 1988 , y en valores porcentuales respecto al total del regadío valenciano se ha pasado de un $17,3 \%$ en el primer año a un $20,3 \%$ en el segundo y a un $26,5 \%$ en el último, relaciones que ponen de manifiesto el modesto significado de estas transformaciones respecto a las acaecidas en el ámbito litoral pero, al mismo tiempo, evidencian el incremento considerable de las proporciones con que contribuyen a la economía agrícola general valenciana.

En este punto es necesario descender a una escala provincial, cuando menos, ya que el incremento de las superficies transformadas no se produce de manera equilibrada en toda la Comunidad. Así, entre 1972 y 1988 las comarcas del interior castellonense experimentaron un crecimiento del regadío cifrado en un $122 \%$, mientras que en las alicantinas fue de un $179 \%$ y en las valencianas de un $180 \%$ en el mismo período.

Todavía son más patentes los desequilibrios por comarcas, con extensos espacios en los que el regadío se mantiene estancado, e incluso decrece, frente a ámbitos más dinámicos, entre los que destacan las comarcas del Campo de Liria, en Valencia, con el 40\% de la superficie del regadío interior de esa provincia, y el Alto y Medio Vinalopó, en Alicante, con el 94\% de la superficie bonificada del interior provincial.

A grandes rasgos, puede decirse que ha sido la concordancia de climas favorables con disponibilidades hídricas subterráneas la que ha posibilitado la expansión de los regadíos interiores, mientras la carencia de esas premisas, o de una de ellas, ha limitado los trabajos de transformación.

\section{Notas sobre la evolución de la explotación de los acuíferos}

En todo el interior valenciano, el aprovechamiento de las surgencias hídricas para la bonificación de pequeños ruedos hortícolas es cuestión atávica. Ahora bien, la utilización de manantiales y aguas caballeras, derivadas por gravedad, comenzó a resultar insuficiente para los intereses agrarios ya en la segunda mitad del siglo pasado, momento en que la elevación de caudales del manto cuaternario mediante norias se hizo frecuente en los fondos de cubetas endorreicas y llanos de inundación. A ese esfuerzo particular se sumó, años más tarde, la captación de caudales más importantes mediante grandes pozos artesianos, perforados por sociedades mercantiles y comunidades de regantes. Tracción animal y fuerza eólica fueron sustituidas por electricidad y gas-oil, nuevas fuerzas motrices que han alcanzado su mayor desarrollo en las últimas décadas, de acuerdo con la expansión reciente de los regadíos. 


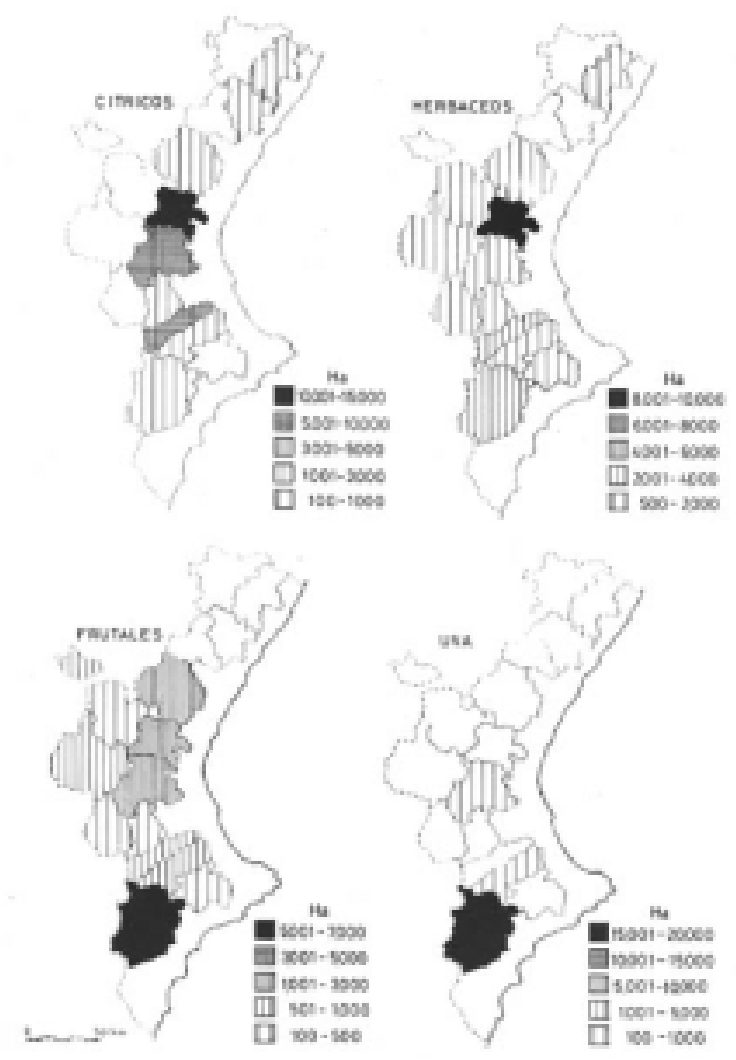

FIGURA 2. Principales cultivos de regadío en las comarcas del interior valenciano. Año 1988. Las comarcas colindantes con las huertas litorales de Valencia manifiestan la expansión hacia el interior de las nuevas plantaciones de cítricos y la demanda de productos herbáceos (hortalizas fundamentalmente) que genera la aglomeración urbana de Valencia. Por el contrario, los regadíos del interior alicantino descansan en la explotación de la uva de mesa y, en menor medida, en los frutales. En los mapas, en blanco quedan las comarcas que no llegan a los umbrales mínimos estimados para cada cultivo. Fuente: C.A., hojas 1-T. Elaboración propia. 


\subsection{Las primeras captaciones}

Comarca pionera en la extracción de aguas subterráneas ha sido la del Vinalopó y, en concreto, el dilatado término municipal de Villena, donde confluyen dos grandes unidades hidrogeológicas (Prebéticos de Murcia y de Alicante). Las surgencias naturales de ambas han sido avenadas por el río Vinalopó, colector que ha bonificado históricamente las huertas de los municipios que jalonan su curso hasta Elche, en un proceso salpicado de enfrentamientos entre las diferentes comunidades de regantes que, desde el siglo XIII cuando menos ${ }^{1}$, han aprovechado no sólo el caudal del río sino también el de numerosos manantiales villenenses, cuyas aguas eran conducidas por el mismo cauce y mediante acequias paralelas.

Hasta finales del siglo pasado, el sistema de riegos de Villena, y de los pueblos aguas abajo del Vinalopó que utilizaban sus excedentes, estaba fundamentado en el aprovechamiento de las aguas caballeras, que manaban por gravedad a partir de fisuras en la roca o mediante pequeñas minas perforadas en su búsqueda. En Villena, dos áreas regadas se repartían esas aguas: la Huerta y la Laguna.

La Huerta, esto es, la superficie regada en las inmediaciones de la ciudad, aprovechaba los caudales emanados de las fuentes abiertas en el mismo callejero, procedentes de la Sierra de San Cristóbal (Sistema acuífero Yecla-Villena-Benejama) aproximadamente con unos 5001/sg, que bonificaban $850 \mathrm{Ha}$.

En la Laguna, desecada en $1803^{2}$, se sucedieron los trabajos de acondicionamiento a lo largo del siglo, culminados con la gestación en 1880 de una Comunidad de Regantes, que aprovechaba las surgencias de agua del manto cuaternario, procedentes por comunicación lateral del Sistema Jumilla-Villena (Prebético de Murcia), con un caudal de 400 1/sg, repartidos por unas 1.200 Ha.

García Martínez ha señalado como cada período de sequía en este ámbito ha ido seguido de un incremento de las captaciones de aguas subálveas ${ }^{3}$, primero mediante norias y desde las últimas décadas de la centuria pasada, merced a las innovaciones técnicas, con la elevación de aguas más profundas mediante pozos artesianos. En Villena, decisiva fue la sequía de 1880-82, que dio pie a la perforación del primer grupo de pozos artesianos en el paraje del Zaricejo (proximidades de la Laguna): 4 abiertos por la Sociedad Atienza, Esteve y Carrió, constituida al efecto en 1883, con un caudal conjunto de $321 / \mathrm{sg}$. Esa misma CUADRO I

VILLENA, 1901-1909. EVOLUCIÓN DE LOS APROVECHAMIENTOS HÍDRICOS

\section{Caudal/sg}

$\begin{array}{lccc}\text { Tipo de riego } & \mathbf{1 9 0 1} & \mathbf{1 9 0 9} & \text { Variación 1/sg } \\ \text { Aguas caballeras Huerta } & 500 & 318 & -182 \\ \text { Aguas caballeras Laguna } & 400 & 21,5 & -378,5 \\ \text { Pozos artesianos } & 259 & 347,4 & +88,4\end{array}$

Fuente: García Martínez, S., 1966, ob. cit.

\footnotetext{
${ }^{1}$ GARCÍA MIRALLES, S.: «Evolución agraria de Villena hasta finales del s. XIX», Cuadernos de Geografía, n. ${ }^{\circ}$, Valencia, 1964 , pp. 179-203.

${ }^{2}$ GIL OLCINA, A.: «La propiedad de la tierra en la Laguna de Villena», Investigaciones Geográficas, n. $^{\circ}$, I.U.G.,1984, Alicante, pp. 7-18.
}

${ }^{3}$ GARCÍA MARTÍNEZ, S.: «La cuestión de las aguas», Villena, n. ${ }^{\circ}$ XVI, Villena, 1966, pp. 5-13. 


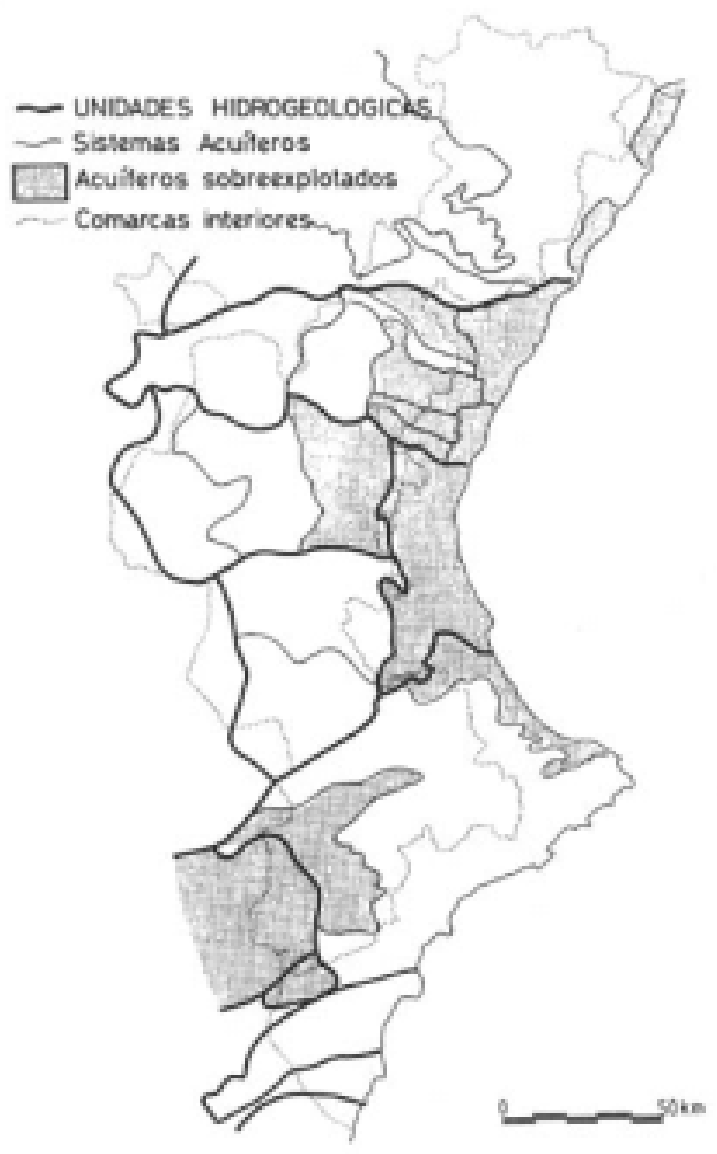

FIGURA 3. Los recursos hídricos subterráneos del interior valenciano. Se observa la concordancia entre acuíferos sobre-explotados y áreas de gran demanda. Fuente: Rodríguez Estrella, J., 1986, ob. cit., Elaboración propia. 
sociedad, dedicada expresamente a la captación y venta de aguas subterráneas, contaba en su patrimonio con 10 pozos en 1909, año en que el número de perforaciones ascendía ya a 20 (16 en el Zaricejo y 4 en la Huerta $)^{4}$.

Una nueva sequía en los primeros años del siglo, junto al incremento de las extracciones, provocaron una notable merma de las aguas caballeras y la indignación consecuente de los antiguos regantes, que se sentían desposeídos de un bien patrimonial perentorio por las nuevas sociedades de explotación de las aguas subterráneas.

Las reiteradas quejas de los regantes de la Huerta y de la Laguna, recogidas por el Ayuntamiento, no fueron nunca atendidas por el amparo que los nuevos explotadores encontraban en la Ley de Aguas de 1879, e incluso en la Ley de Minas, por la práctica al uso de solicitar concesiones mineras para explotar hipotéticos minerales, cuando en realidad se pretendía alumbrar nuevos caudales subterráneos ${ }^{5}$.

Así las cosas, la intervención de la Sociedad Canal de la Huerta de Alicante, y la consiguiente exportación de agua, fue el detonante en la adopción generalizada de la nueva técnica de explotación de los acuíferos. Constituida en 1907 para redotar las huertas de Alicante, San Juan y Muchamiel $^{6}$, en 1909 la Sociedad compró a la Compañía Atienza, Esteve y Carrió la propiedad de 150 1/sg de los pozos del Zaricejo y construyó el notable acueducto que, a lo largo de $55 \mathrm{~km}$, debía conducir el agua a esas huertas litorales, lo que supuso un verdadero agravio para los regantes villenenses, que veían en años de penuria hídrica como salía del municipio casi la mitad del agua aforada y, lo que es más grave, a costa del descenso de los caudales de las aguas caballeras. Asimismo, aguas abajo del Zaricejo, en la Colonia de Santa Eulalia se abrieron siete pozos artesianos, con un caudal conjunto de $1581 / \mathrm{sg}$, adquiridos por la Compagnie Genèrale des Conduits d'Eau, más conocida por la «Compañía Belga», también para el abasto de Alicante ${ }^{7}$.

La ineficacia de las reclamaciones, el descenso continuo de los caudales y su creciente extrañamiento determinaron la rápida adaptación de los agricultores a la nueva situación, de manera que entre 1909 y 1914 fueron construidos 28 nuevos pozos, con un aforo total de 135 $1 / \mathrm{sg}^{8}$, todos ellos practicados por grandes propietarios agrícolas. Los nuevos aprovechamientos ocasionaron otra minoración de las aguas caballeras de la Huerta, que pasaron de los 318 1/sg aforados en 1909 a los 143 1/sg de 1914. Así, el primer paso dado por los antiguos regantes de la Huerta, al convertirse en 1919 en Comunidad de Regantes, fue la perforación de una galería, la Cisura, que proporcionó 500 1/sg. Sin embargo, la Comunidad de la Laguna, por el descenso de los recursos, vio reducir en dos tercios la superficie regada entre la segunda y tercera décadas de la centuria9.

Otras entidades foráneas se sumaron en adelante a la explotación de los acuíferos villenenses, entrando en una espiral de sobre-explotación que hizo preciso trazar un perímetro de protección de la cuenca en $1958^{10}$, año en que ya existían 185 pozos en el municipio (algunos de ellos en manos de las entidades que expresa el cuadro II).

Pese a las limitaciones impuestas a la extracción, el número de pozos y la profundidad

${ }^{4}$ MARIANO VIDAL, L, SÁNCHEZ LOZANO, R.: Estudio de hidrología subterránea en Villena, Villena, 1912, pp. 18-27.

${ }^{5}$ MARIANO VIDAL, L., SÁNCHEZ LOZANO, R.: 1912, ob. cit., pp. 14-15.

${ }^{6}$ FIGUERAS PACHECO, F.: Provincia de Alicante, en G. ${ }^{a}$ Gral. Reino de Valencia, Barcelona, 1913, p. 1.153.

${ }^{7}$ JUAN Y MARCO, F.: Historia de Sax, Villena, 1917, ejemplar mecano, p. 8.

${ }^{8}$ GARCÍA ROS, L.: Estudio de hidrología sobre las relaciones de las Fuentes de Villena y los nuevos aprovechamientos de aguas subterráneas, Villena, 1914, p. 7.

${ }^{9}$ GARCÍA MARTÍNEZ, S.: «Riegos y cultivos en Villena», Saitabi, t. XIX, Valencia, 1969, pp. 302-303.

${ }^{10}$ DUPUY DE LOME, E.: «Perímetro de protección de la cuenca Caudete-Villena-Sax», Notas y Comunicados, IGME, n. ${ }^{\circ} 54,1959$, pp. 93-130. 
CUADRO II

VILLENA, 1958 Y 1985. ENTIDADES EXPLOTADORAS DE AGUAS SUBTERRÁNEAS

$\mathbf{N}^{0}$ pozos

\section{Entidad}

Comunidad Regantes Huerta

C.R. Demarcación Laguna

C.R. La Amistad

C.R. La Armonía

Cía. Centro Levante Riegos

C.R. Aguas de Novelda

C.R. Acequia Mayor

C.R. Aguas de Marchena

Grupo Sindical Colonización 469

\section{Municipio}

Villena

Villena

Villena

Villena

Alicante

Novelda

Elche

Elche

Elda
1958

3

9

2

2

7

7

1

3

2
1985

5

9

2

2

1

19

1

3

1

Fuente: Servicio de Minas, MOPU, Deleg. Alicante, elab. prop.

de los mismos ha ido en aumento, debido tanto a la iniciativa particular como a la ampliación de captaciones de las entidades ya instaladas y de otras nuevas, como Aguas Municipalizadas de Alicante, diversos grupos de colonización y los propios aforos del INC y del IRYDA para el abasto de nuevos regadíos en toda la cuenca del Vinalopó, quedando consolidada por la práctica la exportación de aguas fuera de la cuenca (por ejemplo, la Comunidad de Regantes de Novelda, con 1.800 comuneros y una extensión de 2.056 Ha regables, cuenta con 13 sondeos en Villena, con un aforo conjunto de $911 / \mathrm{sg}$, de los que extrajo 9 millones de $\mathrm{m}^{3}$ en 1986) ${ }^{11}$.

\subsection{La explotación reciente de los acuíferos}

La evolución reciente de las captaciones para las tres subáreas en que se divide la comarca agraria del Vinalopó queda plasmada en el cuadro III, elaborado a partir de los datos del Fichero de Pozos y Sondeos, del Servicio de Minas del MOPU. Se trata, no obstante, de una relación mermada por la ocultación voluntaria de pozos y la indolencia general en la tramitación de las altas: en Villena, por ejemplo, la omisión puede estimarse, aproximadamente, en un $44 \%$ en $1958^{12}$, aunque tal proporción no puede hacerse extensiva a los demás municipios, ni al resto del período analizado.

Llama la atención el elevado número de pozos censado en la Hoya de Castalla, con un excepcional incremento desde los años setenta. Se trata de otra cuenca endorreica, con un importante acuífero detrítico cuaternario en su fondo, flanqueada por tres sistemas: el de Argueña-Maigmó al oeste (calizas del Cretácico, sobre explotado), el de Sierra Mariola al norte (calizas y dolomías del Cretácico, en equilibrio hídrico), y el de Barracones-Carrasqueta al este (calizas eocenas, en equilibrio). La huerta tradicional se ubica sobre la antigua marjal, desecada a partir de una red de azarbes que desagua en el río Verde (también

\footnotetext{
${ }^{11}$ GOZÁLVEZ PÉREZ, V.: «Los agricultores ante la Ley de la Generalitat Valenciana sobre utilización de aguas para riego», Los paisajes del agua, Valencia, Univ. Valencia-Alicante, 1989, pp. 249-246, nota 6.

${ }^{12}$ Según el Fichero, el número de pozos ascendía en ese año a 103, pero la relación ofrecida por el IGME sumaba 185. Ver DUPUY DE LOME, E.: 1959, ob. cit.
} 
Cuadro III

EVOLUCIÓN DEL NÚMERO DE POZOS EN LA COMARCA AGRARIA DEL VINALOPÓ

$\begin{array}{lcccccccc}\text { SUBÁREAS } & \mathbf{1 9 5 0} & \mathbf{1 9 5 5} & \mathbf{1 9 6 0} & \mathbf{1 9 6 5} & \mathbf{1 9 7 0} & \mathbf{1 9 7 5} & \mathbf{1 9 8 0} & \mathbf{1 9 8 5} \\ \text { Alto Vinalopó } & 59 & 107 & 140 & 152 & 207 & 273 & 335 & 392 \\ \text { Medio Vinalopó } & 25 & 41 & 70 & 96 & 140 & 189 & 233 & 282 \\ \text { Hoya de Castalla } & 9 & 63 & 67 & 101 & 198 & 280 & 512 & 720 \\ \text { TOTAL } & 93 & 211 & 277 & 349 & 545 & 742 & 1080 & 1394\end{array}$

Fuente: Servicio Minas, MOPU, elab. prop.

nominado de Castalla, Monnegre y Seco). La elevada humedad del suelo en esa zona hacía casi innecesario el riego para los cultivos tradicionales -cereales fundamentalmente-, aunque ocasionalmente, y sobre todo para cultivos más exigentes, se elevaba el agua del subsuelo o directamente de los azarbes mediante pequeñas norias. Así, en esta subcomarca, la mayor concentración de extracciones, sobre todo de las menores, se da precisamente en la marjal.

No obstante, la transformación en regadío de grandes extensiones de secano sobre los glacis cuaternarios, desde mediados de los años sesenta, hizo necesario la captación de los acuíferos más importantes, ubicados en las calizas y dolomías de las sierras circundantes.

El Vinalopó Medio, ubicado sobre un área de acuíferos menores, sobre-explotados y en avanzado proceso de salinización, presenta el menor número de pozos pese a que sus regadíos son los más exigentes, paliando el desequilibrio con la importación masiva de caudales desde el Alto Vinalopó, explotando pozos ubicados en el curso alto (pero cuya propiedad pertenece a regantes del curso medio), comprando agua a las sociedades mercantiles y los excedentes de los particulares y grupos de regantes del Alto Vinalopó ${ }^{13} \mathrm{y}$, de manera especial, adquiriendo caudales aforados por el IRYDA, hoy pertenecientes a la Conselleria d'Agricultura i Pesca, en vías de concesión definitiva a sus usuarios. Su explotación reciente se resume en el cuadro IV.

La importancia relativa de las extracciones de la cuenca del Vinalopó respecto al conjunto provincial queda reflejada en el cuadro $\mathrm{V}$ y en la figura adjunta. Esa comarca, pese a contar con el $27 \%$ de la superficie agraria provincial, soportaba el $38 \%$ de las explotaciones de aguas subterráneas en la provincia hasta 1960. Desde ese año, la transformación de secanos en todo el ámbito provincial ha ido minorando la proporción alcanzada hasta el equilibrado $27,6 \%$ de 1985.

\footnotetext{
${ }^{13}$ Como ejemplo, la SAT 1.205 de Monforte del Cid, en 1987 hizo las siguientes adquisiciones de agua (en millones de ptas.):

-a IRYDA... 88,2

-a Aralvi S.C.

7,7

-a Mancomunidad del Vinalopó......... 7,2

-a Pozo Garrigós................................. 2,5

-a SAT de Sax................................... 2,3

-a Comunidad Regantes Benajama... 10,0

Total.......

117,9
}

Fuente: SAT 1205, Ejercicio económico 1987 


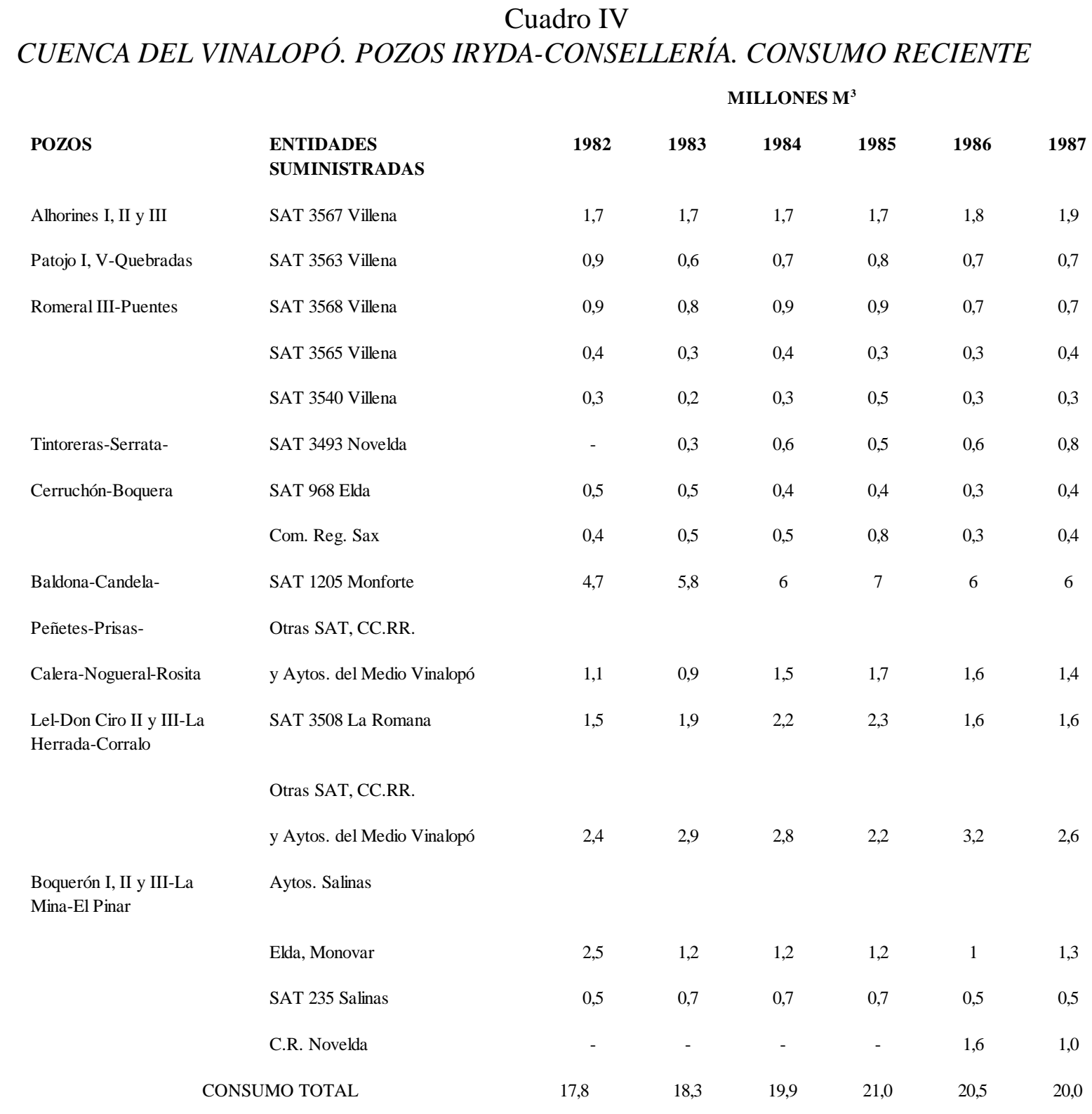

Fuente: IRYDA, Cuenca del Vinalopó, 1988, elab. prop.

En la dinámica general de las perforaciones, el año 1965 supone el inicio de una etapa expansiva que culmina en 1970, coincidiendo con los trabajos del I Plan Cuatrienal de Desarrollo inaugurado en 1964. Los progresos económicos generales se plasman en el incremento de las exportaciones agrarias y del consumo interno, lo que supuso, en concreto para la zona, una notable expansión de la superficie ocupada por uva de mesa, por manzanos, por otros frutales y por hortalizas de gran demanda (especialmente tomate). Todo ello gracias a una política favorable de créditos agrícolas.

Sin embargo, en el lustro siguiente, los cambios experimentados en los organismos y leyes rectores del agro $^{14}$, así como la crisis económica mundial, comenzada a sentir en 1973 y la incidencia del proceso de cambio político, pusieron freno, entro otros aspectos, al proceso de transformación en regadío (o al menos a la legalización de los nuevos aforos)

14 Transformación del SNC en SENPA en 1971, creación del IRYDA en ese mismo año, nueva Ley de Cooperativas de 1972 y Ley de Reforma y Desarrollo Agrario de 1973. 

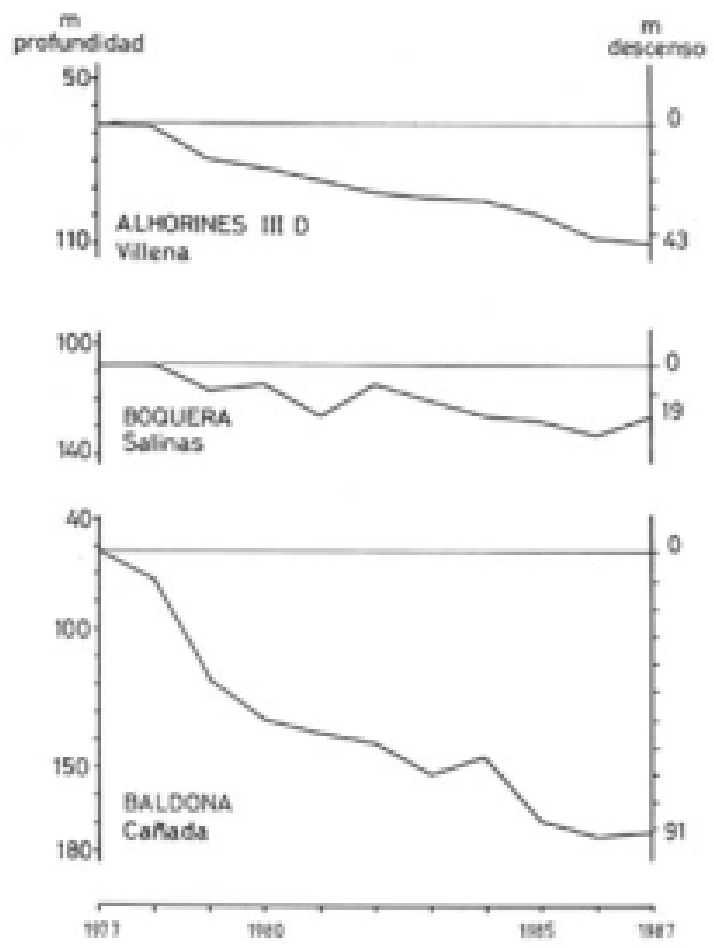

FIGURA 4. Descensos piezométricos recientes en algunos pozos significativos del Alto y Medio Vinalopó. Fuente: IRYDA, 1988. Elaboración propia.

y, como consecuencia directa, en el Vinalopó y en la provincia descendió la inscripción de captaciones hídricas subterráneas.

Entre 1976 y 1980 se asiste a una nueva etapa expansiva posibilitada por el incremento de las inversiones, contenidas en el quinquenio anterior, y por la reanudación de la línea de créditos agrarios, impulsada ahora por las Cajas Rurales y Cooperativas de Crédito locales. Todo ello unido a la declaración de «regadíos de interés nacional», para 


\section{Cuadro V \\ EVOLUCIÓN DE LAS EXPLOTACIONES ACUÍFERAS EN EL VINALOPÓ Y EN EL CONJUNTO PROVINCIAL}

\begin{tabular}{lcccccccc}
\multicolumn{7}{c}{ AÑOS } & & \\
& $\mathbf{1 9 5 0}$ & $\mathbf{1 9 5 5}$ & $\mathbf{1 9 6 0}$ & $\mathbf{1 9 6 5}$ & $\mathbf{1 9 7 0}$ & $\mathbf{1 9 7 5}$ & $\mathbf{1 9 8 0}$ & $\mathbf{1 9 8 5}$ \\
Prov. Alicante & 260 & 554 & 729 & 1057 & 1648 & 2275 & 3755 & 5053 \\
Vinalopó & 93 & 211 & 277 & 349 & 545 & 742 & 1080 & 1394 \\
\% Vinalopó & 35,8 & 38,1 & 38 & 33 & 33,1 & 32,6 & 28,8 & 27,6
\end{tabular}

Fuente: Servicio de Minas, MOPU, elab. prop.

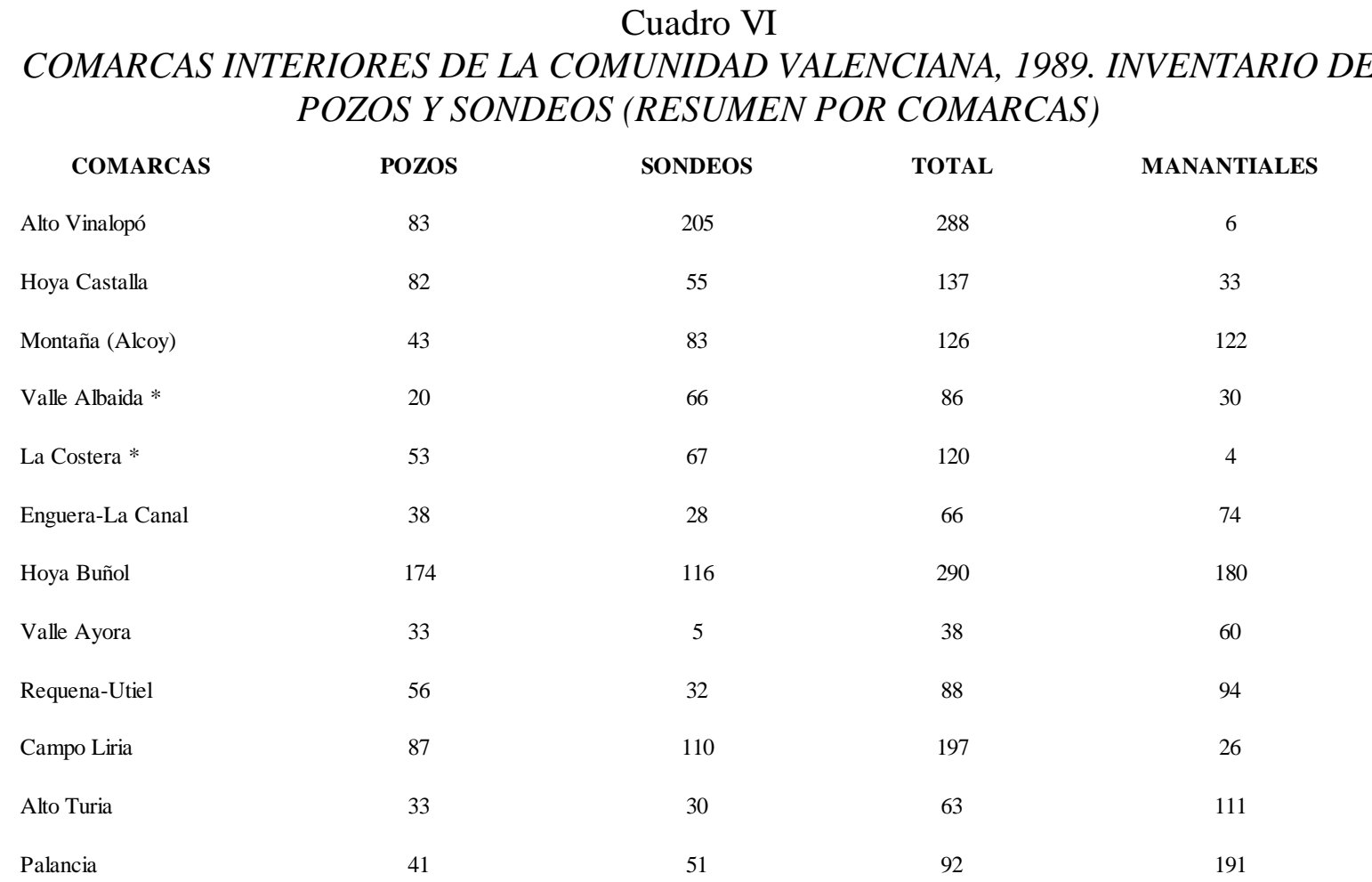

* Sólo municipios del interior.

Fuente: IGME, Valencia, 1989, elab. prop. Faltan por inventariar algunas comarcas.

regular una mejor utilización de las aguas subterráneas, asegurando el regadío existente y la expansión prevista, al quedar la comarca fuera del ámbito dotado por el trasvase Tajo-Segura ${ }^{15}$.

El último período estudiado coincide con el establecimiento de severas restricciones para la expansión del regadío, ante el descenso de los acuíferos y el avance de su salinización. No obstante, la acuciante carencia de aguas, el incremento de los precios y los años de sequía padecidos determinaron nuevas concesiones y, en especial, la intervención del IRYDA para paliar el déficit hídrico.

En las comarcas centrales de Valencia, las transformaciones en regadío a gran escala tienen también su punto de partida en los años sesenta, momento en que, aprovechando la favorable coyuntura exportadora, se produce una gran expansión del naranjal desde las huertas litorales hacia el interior.

15 JUÁREZ SÁNCHEZ-RUBIO, C.: «Mejoras técnicas en el regadío alicantino: disminución del consumo y aumento de la productividad», Demanda y economía del agua en España, Alicante, CAM-Inst. Juan Gil-Albert, 1988, pp. 389-402, p, 395. 


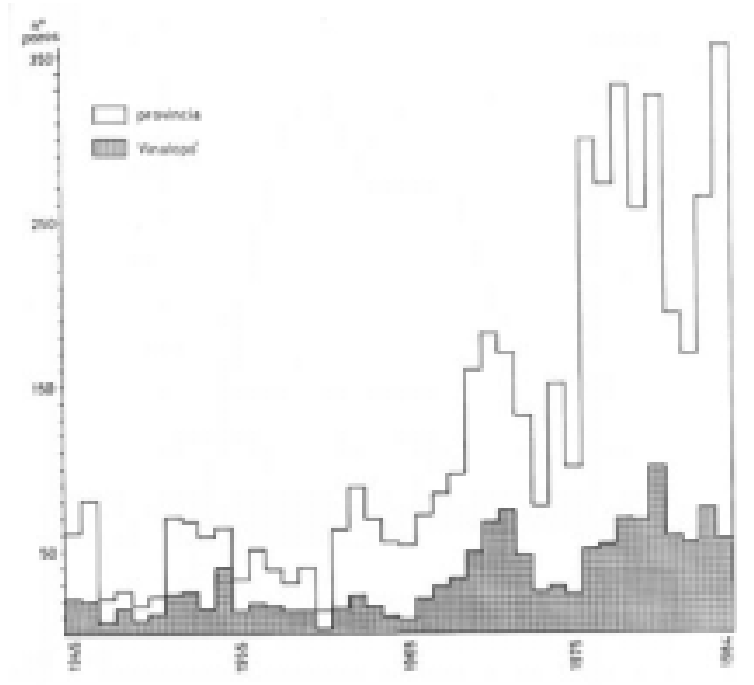

FIGURA 5. Evolución comparada del número anual de perforaciones en la provincia de Alicante y en la comarca del Vinalopó. Se observa la importancia relativa de las extracciones en la comarca respecto al total provincial hasta los años setenta. Fuente: Fichero, IGME. Elaboración propia.

El Campo de Liria se beneficia de unos regadíos mixtos, con un censo total de 197 pozos y 26 manantiales en $1989^{16}$, entre los que la Fuente de San Vicente constituye el más destacado, con un caudal entre 20 y $30 \mathrm{~m}^{3}$ por minuto, origen de una huerta de $700 \mathrm{Ha}$, mejorada desde 1956 por una captación de $12 \mathrm{~m}^{3} /$ minuto de aguas del Turia. A la vez, las acequias de Pedralba, Villamarchante, Benaguacil y Ribarroja riegan unas $3.000 \mathrm{Ha}$. Sin embargo, mayor envergadura que las captaciones subterráneas ha tenido la expansión del regadío debida a la construcción, por parte del IRYDA, del Canal Principal del

${ }^{16}$ IGME, Valencia, 1989, Localización de pozos, sondeos y manantiales, base mapa topogr. 1:50.000. Inventario de realización constante (en el texto se alude también a esta fuente como «Inventario»). 


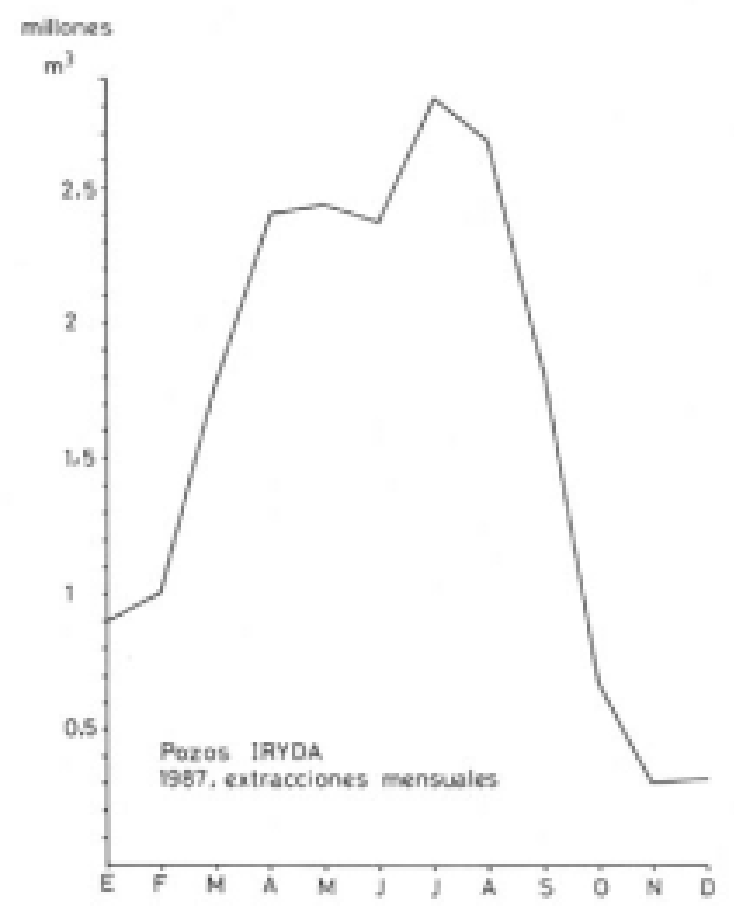

FIGURA 6. Pozos del IRYDA en la cuenca del Vinalopó. Variación mensual de las extracciones en 1987. Se observa el incremento del consumo debido al «riego de primavera» y el alza mayor ocasionada por el «riego de verano». Fuente: IRYDA, Cuenca del Vinalopó, doc. cit. Elaboración propia.

Generalísimo, con una zona regable de $29.441 \mathrm{Ha}$, necesitada de $189 \mathrm{hm} 3 / \mathrm{año}$, de los que 150 $\mathrm{hm}^{3}$ proceden del Embalse del Generalísimo y $39 \mathrm{hm}^{3}$ de pozos ${ }^{17}$. En la misma comarca, el IRYDA ha promovido otra actuación, en Villamarchante-Pedralba, para bonificar 1.994 Ha a partir de 10 pozos con un aforo conjunto de $1,12 \mathrm{~m}^{3} / \mathrm{sg}$.

${ }^{17}$ GOZÁLVEZ PÉREZ, V.: «El mapa del regadío valenciano (1960-1985)», Demanda y economía del agua en España, 1988, ob. cit., pp. 125-138. 


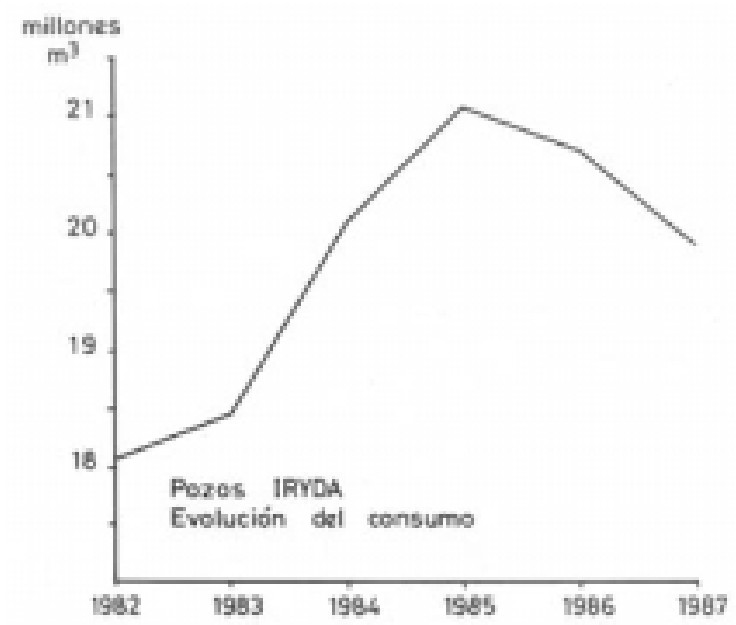

FIGURA 7. Pozos del IRYDA en la cuenca del Vinalopó. Evolución del consumo entre 1982 y 1987 . El descenso en los últimos años se debe a la menor demanda para abasto urbano (por la apertura de pozos municipales) y a la presencia notable de barbechos en las superficies transformadas. Fuente: IRYDA, doc. cit., Elaboración propia.

En la Hoya de Buñol existe un registro de 290 pozos y 180 manantiales, a los que se debe aproximadamente el $70 \%$ de la superficie regada en la actualidad, mientras el resto se beneficia de las aguas del Júcar y del Magro, represado desde 1969 en el Embalse de Forata.

En las comarcas interiores de Castellón, aquejadas en gran parte por la carencia de una topografía, de un clima y de suelos adecuados para los cultivos de regadío, así como por la excesiva profundidad a que se encuentran los depósitos acuíferos en muchos casos (próxima en ocasiones a los $400 \mathrm{~m}$ ), el regadío sigue estancado casi en los mismos márgenes que en décadas anteriores. Las transformaciones son difíciles y costosas, por lo abrupto del terreno y la profundidad de los acuíferos. De manera que la iniciativa pública ha sido escasa, limitada en muchos casos a la captación de aguas para asegurar el abasto de los municipios; mientras la iniciativa privada ha preferido invertir en explotaciones ganaderas integradas. De hecho, existe una fuga de capitales castellonenses hacia los campos del sur de Tarragona para crear nuevos regadíos en ámbitos más favorables ${ }^{18}$.

${ }^{18}$ GOZÁLVEZ PÉREZ, V.: 1988, ob. cit., p.135. 


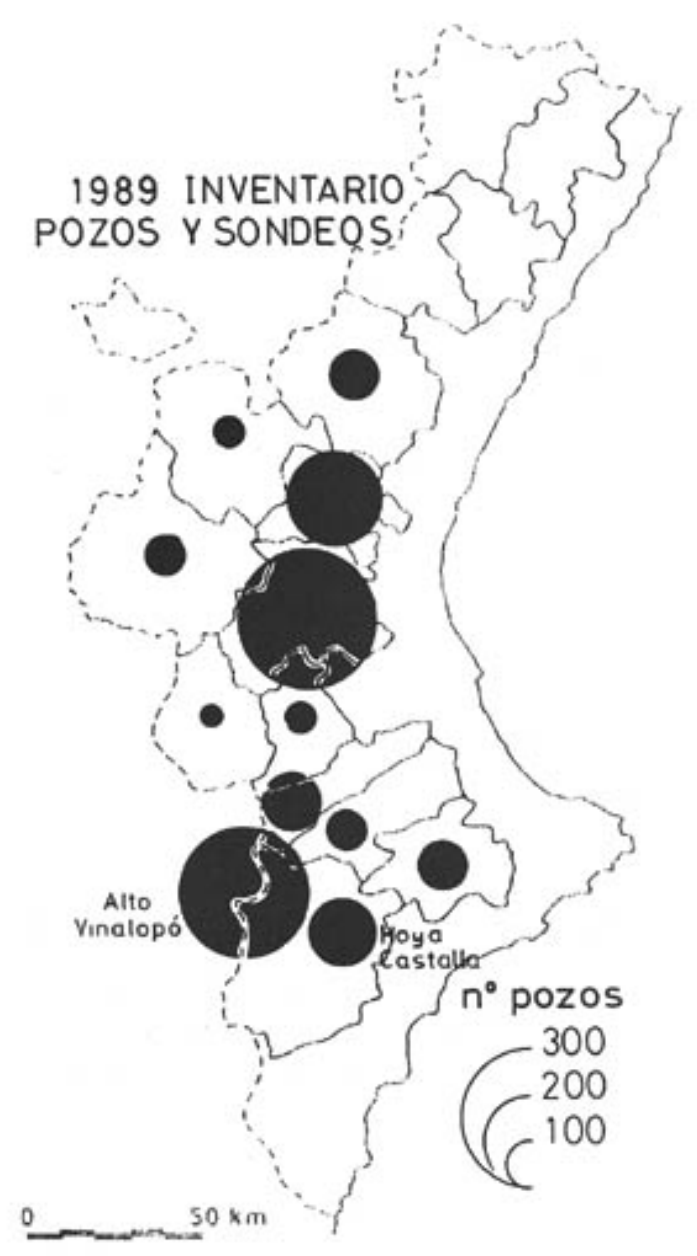

FIGURA 8. Pozos y sondeos en las comarcas del interior valenciano. Se observa la concentración en el Vinalopó (Alto Vinalopó y Hoya de Castalla), en la Hoya de Buñol y en el Campo de Liria, comarcas con mayor expresión de tierras regadas. En blanco quedan las comarcas de las que no se disponen datos. Fuente: IGME, Inventario cit. Elaboración propia.

\section{Propiedad y venta del agua}

La nueva Ley de Aguas, en vigor desde 1986, define el carácter público de todas las aguas y regula su aprovechamiento comunal o privado mediante las oportunas autorizaciones y concesiones; cabe por ello hablar con mayor propiedad de los diferentes tipos de tenencia del agua que afectan a los regadíos interiores y a las formas de uso desplegadas para su aprovechamiento.

En el ámbito interior de la Comunidad Valenciana, la captación y el aprovechamiento de las aguas subterráneas adquieren gran diversidad, aunque existen cuatro modalidades más o menos definidas a las que se ajustan la mayoría de las explotaciones. Los modelos son los representados por las Comunidades de Regantes, las Sociedades Agrarias de 
Transformación (SAT), las sociedades mercantiles y los pequeños propietarios de pozos, aunque es preciso destacar que las diferencias en la regulación de las aguas son notables incluso en el seno de cada uno de esos grupos.

\subsection{Las Comunidades de Regantes}

En general, las Comunidades de Regantes, propietarios antes de las aguas caballeras por antiguas disposiciones legales, o por derecho consuetudinario, en la actualidad o poseen pozos propios de los que se abastecen totalmente, como la C.R. de la Huerta de Villena, o tienen que comprar el agua al IRYDA, como la C.R. de Sax, o llevan un régimen mixto mediante el que aprovechan aforos propios y aguas del IRYDA, como la C.R. de Novelda. En los tres casos, el régimen de tenencia de agua implica valores diferentes en el precio final de adquisición por parte del agricultor, que puede pagar sólo el coste de la elevación y una mínima cantidad de gestión, o un valor más elevado por la necesidad de amortizar obras de infraestructura e inversiones de carácter general. En cualquier caso, los precios que paga el agricultor, exentos de IVA por tratarse de organismos públicos, se encuentran muy ajustados a los costes de explotación, sin que haya beneficio neto en el balance anual.

Mención aparte merecen las comunidades que subastan el agua entre sus miembros, como la de Novelda, régimen de licitación con el que se persigue paliar, mediante el incremento estival de precios, los déficits invernales acumulados por el descenso de la demanda, presentando a foral de año un balance igualmente equilibrado, o con algunos beneficios que son reinvertidos en obras de carácter general.

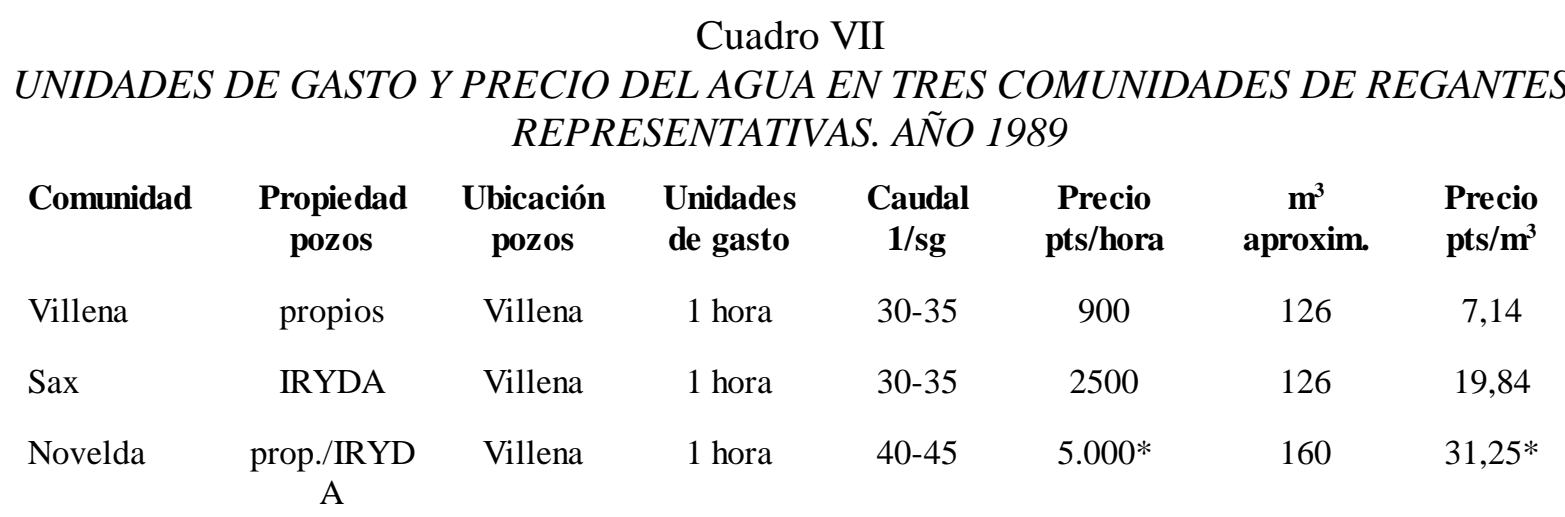

* Precio medio estimado

Fuente: CC.RR. citadas, elab. prop.

\subsection{Las Sociedades Agrarias de Transformación}

Al aprobarse en 1981 el Estatuto que regulaba las Sociedades Agrarias de Transformación se produjo la conversión de los antiguos Grupos Sindicales de Colonización en modernas SATs, esto es, en agrupaciones de agricultores de carácter privado, con responsabilidad limitada a su patrimonio social. En 1988, el número de SAT dedicadas a la administración de riegos ascendía a 315 en toda la Comunidad Valenciana: de ellas 113 (el 36\% aproximadamente) tenían sede en las comarcas del interior.

Estas sociedades, creadas para la promoción del riego en las tierras de sus asociados, explicitan en sus reglamentos los medios previstos para conseguir tal fin: a) captación y 
Cuadro VIII

LA SAT Y EL REGADÍO EN 1988

Total SAT $\begin{gathered}\text { SAT. admón. } \\ \text { riegos }\end{gathered} \quad$ Comarcas Interior

$\begin{array}{lcccc} & & & \mathbf{n}^{\mathbf{0}} \mathbf{S A T} & \mathbf{n}^{\mathbf{0}} \text { socios } \\ \text { Alicante } & 170 & 84 & 32 & 10.641 \\ \text { Castellón } & 198 & 62 & 5 & 470 \\ \text { Valencia } & 448 & 169 & 76 & 11.698 \\ \text { TOTAL } & 816 & 315 & 113 & 22.809\end{array}$

Fuente: Ministerio A.P.A., Entidades asociativas agrarias, elab. prop.

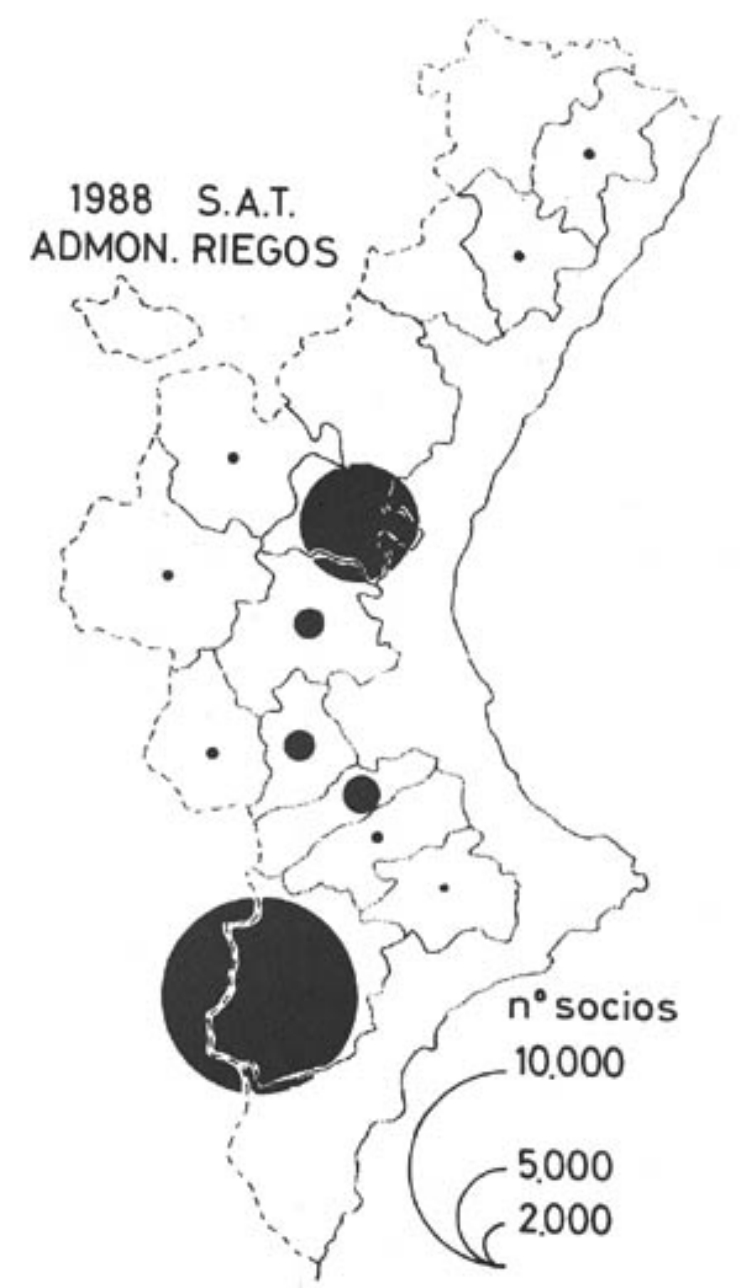

FIGURA 9. SAT dedicadas a la administración de riegos en las comarcas del interior valenciano. El Vinalopó y el Campo de Liria presentan las iniciativas asociacionistas más destacadas. Fuente: Minist. A.P.A., Entidades asociativas agrarias, 1988. Elaboración propia. 


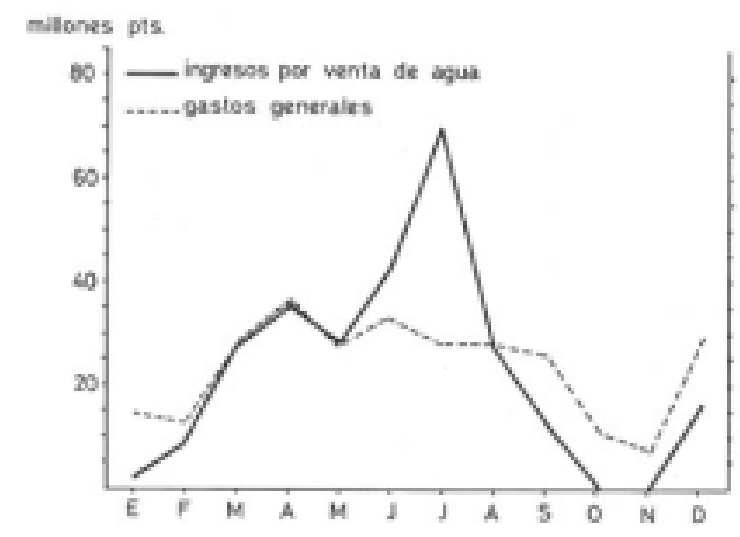

FIGURA 10. SAT. N. ${ }^{\circ} 3819$, Aspe. Balance mensual de ingresos por venta de agua y de gastos generales. El saldo positivo estival compensa el déficit invernal, mientras en primavera se da un manifiesto equilibrio. Fuente: SAT. cit., Ejercicio 1988. Elaboración propia.

adquisición de aguas de riego, b) alumbramiento y distribución de aguas para tal finalidad, c) regulación de caudales hídricos, d) red de acequias y de canales, e) fomento del estudio de nuevos sistemas de regadío y formación e instrucción del agricultor, f) proyección, financiación y ejecución de obras y mejoras de interés general para los asociados y explotación, administración y conservación de las mismas ${ }^{19}$.

Ajustadas al Estatuto general definido por Real Decreto de 3 de agosto de 1981, las SAT reconocen como socios, bien sólo a los propietarios con título inscrito a su nombre en el Registro de la Propiedad (caso de las SAT Virgen de las Nieves de Aspe y Monteagudo de Novelda), o bien a las personas físicas o jurídicas que ostenten la titularidad, en propiedad, arrendamiento o usufructo de las explotaciones agrarias (caso de las SAT de Sax y Aguas de Monforte). En todos los casos, el derecho a riego se halla unido inseparablemente a las tierras de los asociados, no pudiendo separarse de las mismas. El precio del agua es fijado por cada Junta Rectora de acuerdo con el coste inicial y las amortizaciones pendientes; en caso de no ser suficiente para saldar positivamente el balance anual, los déficits se cubren mediante oportunas derramas entre los asociados.

Por tratarse de entidades asociativas de carácter privado, sus miembros han de hacer frente, además de a los gastos generales de amortización, al pago de un 6\% de IVA en cada tanda de agua contratada. Ocasionalmente, también deben afrontar derramas o pagar

\footnotetext{
${ }^{19}$ Todas las SAT recogen en sus «Estatutos» los mismos objetivos y medios. Ver, p.e., Estatutos de SAT Aguas de Monforte o de SAT de Sax, en sus artículos $4 .^{\circ}$
} 
una cuota fija mensual (100 pts. por tahúlla en la SAT Virgen de las Nieves de Aspe, en 1989) para compensar los déficits ocasionados por la venta de agua a los socios a precios por debajo de su coste real.

\section{Cuadro IX \\ SAT VIRGEN DE LAS NIEVES, ASPE. SUBVENCIÓN DEL COSTE DEL AGUA AL USUARIO, 1988}

Precio medio coste fluido eléctrico (hora) $4.319,13$ ptas.

Precio medio coste hora de agua. $10.683,81 \ll$

Precio medio de venta hora de agua $. .4 .207,16 \ll$

Horas de agua vendidas $15.262,50 \ll$

Fuente: SAT 3819, Ejercicio 1988.

En todos los casos, al igual que en las Comunidades de Regantes, la unidad de gasto empleada es la hora, de fácil medida por agricultores y acequieros, que obliga a que toda la red de conducciones tenga la misma sección, de manera que el caudal transportado en ese lapso de tiempo sea el mismo en cualquier ramal que surca la superficie regable.

El tipo de licitación ordinario se basa en unos precios fijos establecidos por los mismos asociados, donde entran gastos de extracción o compra del agua, más los derivados de la gestión, siempre buscando minorar el coste del agua para el regante, atendiendo a un balance anual positivo del ejercicio.

\begin{tabular}{|c|c|c|c|c|c|c|c|}
\hline \multicolumn{8}{|c|}{$\begin{array}{c}\text { Cuadro X } \\
\text { UNIDADES DE GASTO Y PRECIOS DEL AGUA EN ALGUNAS SAT, AÑO } 1989\end{array}$} \\
\hline S.A.T. & $\begin{array}{l}\text { Propiedad } \\
\text { pozos }\end{array}$ & $\begin{array}{l}\text { Unidades } \\
\text { de gasto }\end{array}$ & $\begin{array}{l}\text { Caudal } \\
1 / \mathrm{sg}\end{array}$ & $\begin{array}{l}\text { Precio } \\
\text { pts } / \mathbf{h}\end{array}$ & $\begin{array}{l}\text { Tipo de } \\
\text { licitación }\end{array}$ & $\mathbf{m}^{3}$ aprox. & $\begin{array}{l}\text { Precio } \\
\text { pts/m }\end{array}$ \\
\hline $\begin{array}{l}\text { Ayora } \\
2717\end{array}$ & propios & $1 \mathrm{~h}$ & - & - & precio fijo & - & 3 \\
\hline $\begin{array}{l}\text { Villena } \\
3563\end{array}$ & prop./IRYDA & $1 \mathrm{~h}$ & $28-30$ & 1000 & precio fijo & 108 & 9,25 \\
\hline Sax 3562 & propios & $1 \mathrm{~h}$ & 36 & 1700 & precio fijo & 130 & 13,07 \\
\hline $\begin{array}{l}\text { Novelda } \\
3493\end{array}$ & IRYDA & $1 \mathrm{~h}$ & 50 & 3305 & precio fijo & 180 & 18,36 \\
\hline $\begin{array}{l}\text { Hondón } \\
\text { F. } 3501\end{array}$ & mercantil & $1 \mathrm{~h}$ & 50 & 3400 & precio fijo & 180 & 18,88 \\
\hline $\begin{array}{l}\text { Monforte } \\
1205\end{array}$ & prop./IRYDA & $1 \mathrm{~h}$ & $55-60$ & $7.045^{*}$ & subasta & 216 & 32,61 \\
\hline $\begin{array}{l}\text { Aspe } \\
3819\end{array}$ & propios & $1 \mathrm{~h}$ & 40 & d 5.700 & precio fijo & 144 & 39,58 \\
\hline & & & & n 5.200 & y subasta & 144 & 36,11 \\
\hline
\end{tabular}

* Preciọ medio estimado (precio partida: 3.500 pts.; precio máximo: 8.376 pts. -julio-)

d: Precio venta durante el día; n: precio durante la noche.

Fuente: SAT citadas, encuesta prop.

No obstante, el derecho consuetudinario, en algunos casos, y las nuevas técnicas, en otros, introducen modificaciones en los precios de venta del agua. Así, en el Vinalopó Medio es común desde hace siglos la adjudicación de las tandas de riego mediante subastas, sistema mantenido, bien que con regulaciones que limitan posibles compras abusivas, ya que permite obtener beneficios durante el riego de verano, cuando mayor son las demandas $y$ el precio del agua, que generan un pasivo que permite afrontar con liquidez los 


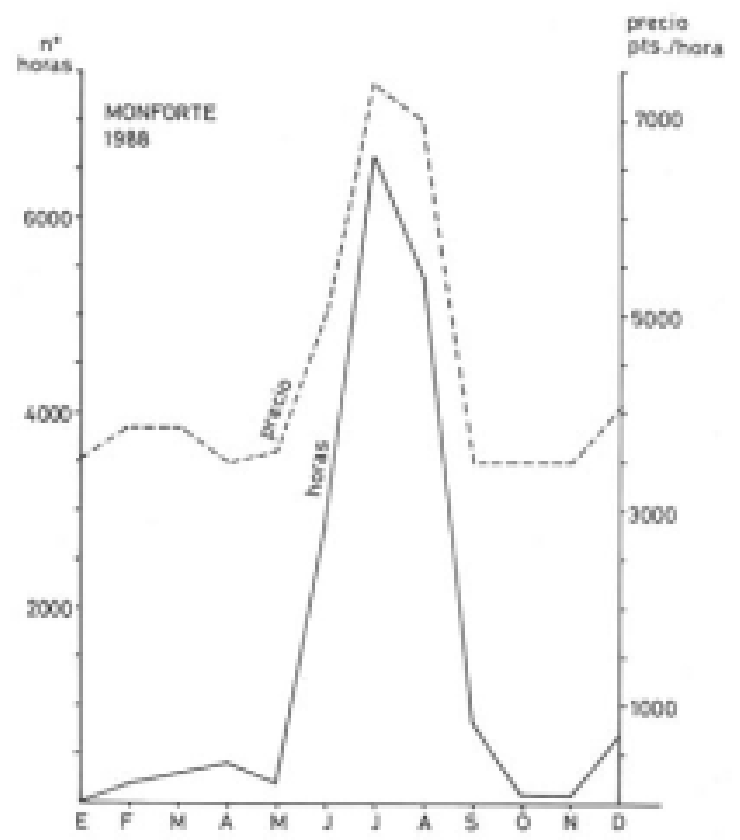

FIGURA 11. SAT. N. ${ }^{\circ}$ 1205, Monforte. Evolución mensual del consumo de agua (en horas vendidas) y de su precio. Año 1988. Fuente: SAT. Cit., encuesta propia.

gastos (créditos fundamentalmente) durante los momentos en que decae el consumo. En las Comunidades de Regantes, en las que tierra y agua están disociadas, cada comunero puede adquirir el volumen de agua que estime oportuno, de acuerdo con su capacidad económica, independientemente de la superficie de tierra poseída. Sin embargo, el régimen de las SAT permite comprar agua libremente en subasta sólo hasta un máximo de 2 horas por tahúlla y año. 
Cuadro XI

EVOLUCIÓN MENSUAL DEL PRECIO DEL AGUA EN LA SAT DE MONFORTE, 1989

$\begin{array}{lcclcr} & \text { horas } & \text { pts/h } & & \text { horas } & \text { pts/h } \\ \text { Enero } & 5,5 & 3.500 & \text { julio } & 6.627,25 & 8.376 \\ \text { Febrero } & 200,75 & 3.853 & \text { agosto } & 5.381,75 & 8.005 \\ \text { Marzo } & 296,25 & 3.827 & \text { septiembre } & 820,5 & 3.535 \\ \text { Abril } & 396,25 & 3.500 & \text { octubre } & 89,5 & 3.500 \\ \text { Mayo } & 233,25 & 3.607 & \text { noviembre } & 88 & 3.500 \\ \text { Junio } & 2.859,75 & 4.973 & \text { diciembre } & 693,5 & 4.085\end{array}$

Total horas vendidas: $17.692,25$

Precio medio pts./h.: 7.044,85

Fuente: SAT. Monforte, encuesta prop.

Cabe indicar que, en años de abundancia pluviométrica, el descenso en la demanda de riego puede invalidar las subastas y el agua se adjudica directamente al precio de partida, que permanece inamovible. Por el contrario, años de sequía provocan espectaculares incrementos en los precios del riego de verano: en julio de 1986 llegó a pagarse a 20.000 pts la hora en la SAT de Aspe (aproximadamente a 139 pts. $/ \mathrm{m}^{3}$ ).

Por otro lado, la incorporación lenta pero constante de riegos localizados, con sus pequeños embalses particulares, permite al agricultor hacer acopio de agua cuando el precio es bajo (durante el invierno, o por la noche merced a la reducción de la tarifa eléctrica), de ahí que algunas SAT, como la de Aspe, mantengan a lo largo del año precios diferentes durante el día y la noche.

\subsection{Sociedades mercantiles de explotación de agua}

Desde los primeros tiempos, el afloramiento de caudales subterráneos y su envío a otras cuencas ha estado ligado a la configuración de sociedades mercantiles, amparadas por la Ley de Aguas de 1879, e incluso por el Reglamento de Minas de 1905, con la finalidad exclusiva de obtener un beneficio económico en la transacción. Una de las primeras conocidas fue la compañía formada en Villena por los señores Atienza, Esteve y Carrió para extraer aguas en el paraje del Zaricejo, en 1883. A esta siguieron, en el mismo ámbito, la Sociedad del Canal de la Huerta de Alicante, constituida en 1907 y reconvertida después en sociedad anónima que, todavía en activo, vende el agua extraída de Villena a regantes de los municipios de la Huerta alicantina y ofrece, también, suministros en otros términos por los que atraviesa el canal (Elda, Petrer, Novelda, Monforte, Agost y San Vicente), y la «Compañía Belga», que satisfacía el abasto de la ciudad de Alicante.

Después del ecuador de la centuria han ido apareciendo numerosas empresas, de diferente envergadura, para la extracción y venta del agua subterránea en la zona, casi siempre con capitales generados en la industria. Entre las más importantes cabe destacar la Compañía Centro Levantino de Riegos y Captaciones, Aguas Municipalizadas de Alicante y Riegos la Salud, mientras que otras menores han proliferado por los diferentes municipios del área, sobre todo para cubrir la demanda generada por el desarrollo industrial y, de manera especial, la debida a las residencias secundarias. 
Riegos la Salud S.A., conocida también por el «Pozo de los Suizos», que suministra agua a la SAT San Antón de Hondón de los Frailes, y a otros grupos de regantes, resulta un claro exponente de gran empresa de explotación de aguas. En 1966, una sociedad helvética, con participación española, realizó una perforación en la Sierra de Crevillente que dio un aforo de $7501 / \mathrm{sg}$, constituyéndose la compañía Riegos la Salud S.A. para su explotación. La mayor parte del agua alumbrada está destinada a cubrir las exigencias de regadíos ubicados en pedanías de Orihuela, Albatera y Crevillente, entre cuyos regantes la sociedad repartió acciones y comercializa el agua a precios de libre mercado, dando lugar a una cierta especulación por acopio y reventa ${ }^{20}$. En Hondón de los Frailes, el antiguo Grupo Sindical de Colonización hizo cesión indefinida a Riegos la Salud de la parte de explotación del acuífero de la Sierra de Crevillente a que tenía derecho a cambio de obtener siempre los primeros $100 \mathrm{l} / \mathrm{sg}$ extraídos, a precios medios orientados por las tarifas vigentes en Riegos de Levante ${ }^{21}$. No obstante, en la actualidad se ha producido un notable desfase entre los precios marcados por una y otra compañía, de manera que, mientras Riegos de Levante cobraba en 1981 a 1.500-1.700 pts/hora, Riegos la Salud, esgrimiendo como argumento el notable descenso piezométrico del acuífero, lo hacía a 3.000-3.400 pts,/hora, cuestión que ha motivado un serio enfrentamiento en los últimos años entre sociedad explotadora y regantes, que consideran incumplido el contrato por un exceso de extracción de aguas del que son ajenos.

Por otra parte, la empresa «Agua Sax S.L.» puede servir de modelo de pequeña explotación dedicada básicamente al abasto de chalés. La empresa, constituida para explotar un pozo con un aforo escriturado en $451 / \mathrm{sg}$, desplegó una serie de conducciones sobre varias pedanías agrarias, convertidas en auténticas zonas de recreo de tipo ciudad jardín por la proliferación de residencias secundarias, realizando un contrato de compra-venta entre los interesados, que debían pagar una cantidad inicial por derechos de obra y conexión a la red (en la actualidad alrededor de 150.000 pts.), satisfacer todos los impuestos, cargas y gravámenes derivados del contrato y hacer frente a un canon mensual, cifrado en 1.500 pts. en 1989 , mediante el cual acceden a un suministro de $30 \mathrm{~m}^{3}$ al mes. La cuota es inamovible si no llega a consumirse el volumen de agua contratado (como de hecho sucede durante los meses de octubre a junio), de manera que, aunque el coste teórico durante ese período sea de $50 \mathrm{pts} . \mathrm{m}^{3}$, el real, dado el bajo consumo invernal, excede con creces ese valor. Sin embargo, el exceso de consumo ha de satisfacerse a $70 \mathrm{pts} . \mathrm{m}^{3}$. Cada año se revisa la tarifa, procediéndose a un incremento paralelo al fijado por el INE como variación en el coste de la vida. Cabe indicar que el agua se destina fundamentalmente a uso doméstico y recreativo (de hecho, las piscinas cuentan por término medio con esos $30 \mathrm{~m}^{3}$ de capacidad).

En la actualidad existen unos 450 abonados, que pueden ver rescindidos sus contratos por impago de dos cuotas mensuales, o por agotamiento del acuífero, sin percibir por ello compensación alguna. El contrato recoge también una posible merma en la dotación de agua si disminuyera el aforo, hecho que ya se ha dado, con las consiguientes secuelas de incertidumbre y malestar entre los abonados.

${ }^{20}$ COSTA MAS, J.: «Cambios de estructuras al sur de Alicante (Aproximación al mercado de la tierra)», $L a$ propiedad de la tierra en España, Alicante, Dpto. Geografía, Univ. Alicante, 1981, pp. 419-436, p. 425.

${ }^{21}$ En 1967, por discrepancias internas, un grupo de asociados decidió separarse y crear una nueva SAT, la «San Isidro», con $\mathrm{n}^{\circ}$ 3496, pero conservando el derecho a la parte proporcional de agua derivada de los $1001 / \mathrm{sg}$. 


\subsection{Los pequeños propietarios de agua}

La sed de agua en los secanos del interior, la euforia de las transformaciones en laderas y la difusión de las modernas técnicas de captación y distribución de aguas subterráneas, que permiten instalar equipos particulares con costes viables para la explotación agraria, se encuentran en el origen de la proliferación de pequeñas perforaciones para uso privado, de imposible cuantificación por los motivos ya aludidos de dejación de las obligaciones fiscales y la dificultad de establecer un recuento de campo. Por otro lado, la nueva Ley de Aguas no exige licencia o concesión expresa para los pozos cuya explotación no exceda los $7.000 \mathrm{~m}^{3}$ /año (Art. 52.2), lo que agrava las dificultades de medición de esas pequeñas explotaciones. Se trata de medianos y grandes empresarios agrarios, con capital suficiente para transformar parte o todas sus tierras (aunque lo normal es que la operación se financie mediante créditos agrarios y subvenciones), de importantes compañías de productos agrarios,

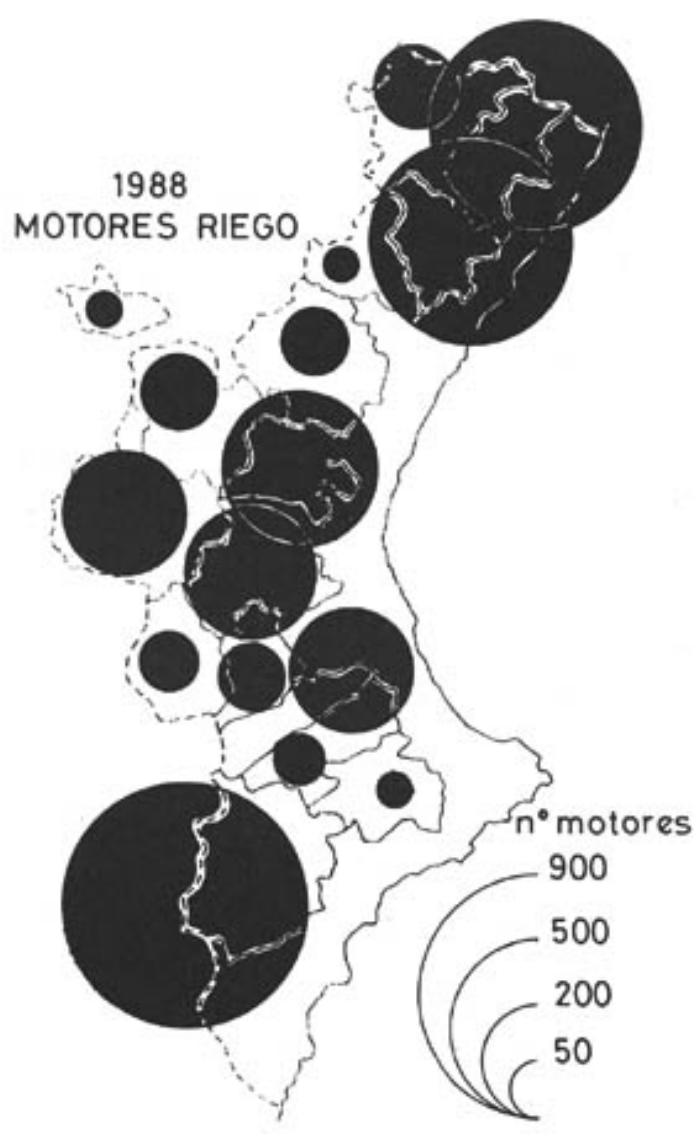

FIGURA 12. Motores para riego en las comarcas del interior valenciano, año 1988. El Vinalopó alcanza el primer puesto seguido de las comarcas ganaderas de Castellón y de las colindantes a la Huerta de Valencia. Fuente: Consellería Agricultura, 1988. Elaboración propia. 
como BONY S.A. y ETASA ${ }^{22}$, y de industriales o profesionales liberales que invierten en transformación de nuevos regadíos ${ }^{23}$. En estos casos, los aforos se encuentran sobre las mismas tierras que bonifican y la propiedad del agua es exclusiva del propietario del pozo, que puede vender los sobrantes a otros regantes o para uso urbano e industrial. Si el agua se emplea exclusivamente en el riego del predio, su costo radica sólo en las cargas de extracción (tarifa eléctrica o gas-oil), mientras que si se comercializan los sobrantes, el propietario añade un margen de beneficios muy variable según los casos, aunque siempre orientado por los precios vigentes en el entorno.

Teniendo en cuenta las carencias apuntadas, el Inventario de Pozos y Sondeos, que realiza de manera ininterrumpida el IGME (aunque todavía incompleto), y el Censo de Motores de Riego, elaborado por las Cámaras Agrarias, pueden dar una idea aproximada del número de pozos y de su distribución por las comarcas del interior de la Comunidad Valenciana, cuyos valores se reflejan en el cuadro XII.

Al comparar ambas fuentes (en las comarcas en que es posible) se observa, en primer lugar, una mayor inscripción de motores para riego que de pozos, debida al mayor control

\section{Cuadro XII \\ 1988-89, DISTRIBUCIÓN COMARCAL DE MOTORES DE RIEGO, POZOS Y SONDEOS \\ MOTORES DE RIEGO \\ POZOS}

\section{COMARCAS}

Alto Maestrazgo

Bajo Maestrazgo

Llanos centrales

Peñagolosa

Palancia

Total interior Castellón

Rincón de Ademuz

Alto Turia

Campo de Liria

Requena-Utiel

Hoya Buñol

Valle Ayora

Enguera-La Canal

La Costera

Valle de Albaida

Total interior Valencia

Vinalopó

Montaña

Total interior Alicante

Total interior Comunidad

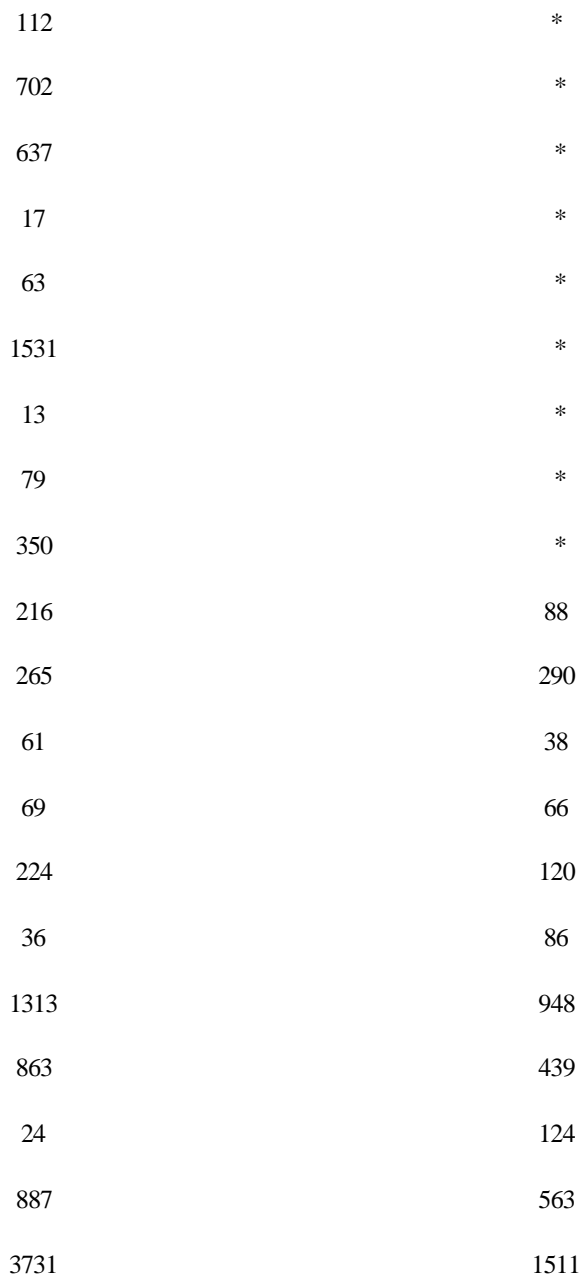

*Sin datos. Fuente: IGME, 1989, C. Agricultura, 1988, elab. prop.
88

290

38

66

120

86

948

439

124

1511

${ }^{22}$ BRU RONDA, C.: «Nuevas formas de tenencia de la propiedad del agua en el Campo de Alicante», Investigaciones geográficas, n. ${ }^{\circ}$, Alicante, 1984, I.U.G., pp. 105-113.

${ }^{23}$ GOZÁLVEZ PÉREZ, V.: «Las grandes explotaciones agrarias actuales en el País Valenciano», La propiedad de la tierra en España, 1981, ob. cit., pp. 213-232. 
impositivo y fiscal que lleva parejo la adquisición de las motobombas y motores; mientras que, con frecuencia, la apertura de pozos y galerías se realiza sin previa licencia y ocasionalmente no llegan a legalizarse (es común la presencia en las parcelas beneficiarias del agua de brocales de pozos ocultos o camuflados).

Por otro lado, de acuerdo con la distribución espacial de las explotaciones acuíferas, se detecta la concordancia de ambas fuentes en señalar la importancia de las comarcas del Vinalopó, del Campo de Liria y de la Hoya de Buñol. Cabe, no obstante, poner de manifiesto el elevado censo de motobombas en las comarcas castellonenses del Bajo Maestrazgo y de los Llanos centrales, que se contrapone al volumen de tierras regadas (ver mapa superficie regada en 1988). Tal circunstancia se debe a dos hechos fundamentales, como son, por una parte, el bajo nivel asociativo de los agricultores de esas comarcas, como pone de manifiesto el escaso número de SAT registrado (ver mapa SAT), que obliga a los agricultores a disponer de sus propios equipos de riego; y por otra parte, a la preferente dedicación de esas comarcas a la ganadería intensiva ${ }^{24}$, necesitada también de importantes dotaciones hídricas de uso privativo.

\section{Conclusiones}

De acuerdo con la distribución de los recursos, puede decirse que los acuíferos en las comarcas del interior valenciano son excedentarios precisamente allí donde las condiciones climáticas, topográficas y edáficas limitan su extracción a una demanda escasa (lo que sin duda contribuye a ese superávit), mientras que en las comarcas agrícolas más importantes, con mayor presencia de regadío, como son el Campo de Lirira, la Hoya de Buñol y el Valle del Vinalopó, los acuíferos son más reducidos y la sobre-explotación padecida les ha llevado, ocasionalmente, a cotas de insalubridad y de inaptitud agrícola por su extrema salinización.

Desde los primeros momentos, la explotación de esos recursos subterráneos suscitó pleitos y enconamientos por la carencia de una adecuada legislación, por el uso interesado que se ha hecho de las normas existentes, por la ausencia de verdaderos agentes de control y por el marcado carácter especulativo introducido por las compañías ajenas al trabajo de la tierra. Todavía hoy, el reglamento de la nueva Ley de Aguas se transgrede con notable impunidad: no dar el alta oportuna de la explotación, omitir parte del aforo, profundizar la perforación aprovechando licencias para «limpiar los pozos» pese a la prohibición expresa, o desviar caudales entre cuencas y de uno a otro uso (de agrícola a industrial y residencial), entre otras, son prácticas comunes, dada la carencia de una adecuada inspección y la permisibilidad de las Administraciones por la importante cuestión social que subyace.

Por lo que respecta al uso y venta del agua, se observa como el omnímodo poder de las antiguas Comunidades de Regantes se ha visto cercenado por las nuevas formas de explotación, puestas en marcha por sociedades mercantiles, SAT y pequeños explotadores. Como norma, todos utilizan la «hora» como unidad de gasto y gestión, aunque con caudales y precios diferentes incluso dentro del mismo municipio. En general, puede seguirse un incremento gradual del precio del agua desde las zonas donde ésta es más abundante hasta las comarcas que padecen escasez, debido a las cargas de infraestructura y gestión y a la intermediación de empresas privadas u organismos públicos que padecen, o de que se benefician, los regantes.

En definitiva, el agua constituye en este ámbito interior un decisivo factor de progreso económico, con importantes repercusiones en la modelación del paisaje, que exige una más acertada regulación y gestión pública y privada.

${ }^{24}$ OBIOL MENERO, E. M.: «La nueva orientación ganadera de las comarcas de Castellón», III Col. Nac. Geografía Agraria, Jarandilla de la Vera, 1985, pp. 319-327. 